\title{
Access to cardiac rehabilitation and the role of language barriers in the provision of cardiac rehabilitation to migrants
}

\author{
Fatima Al-Sharifi ${ }^{1 *}$ (D, Hanne Winther Frederiksen ${ }^{1,3,4}$, Henriette Knold Rossau ${ }^{2}$, Marie Norredam ${ }^{3}$ and \\ Ann-Dorthe Zwisler ${ }^{2}$
}

\begin{abstract}
Background: Cardiac rehabilitation (CR) has proven health benefits and, according to international guidelines, CR must be offered to all eligible patients. Studies have reported lower uptake of CR among migrants, and migrants are known to face several barriers in their access to healthcare, of which language is the most common. The aim of this study is to examine the provision of CR core components for migrants; and the role of language barriers in the provision of CR in Danish hospitals and municipalities.

Methods: This is a descriptive study based on repeated nationwide surveys conducted in 2013 and 2015 by the Danish Cardiac Rehabilitation Database. The surveys collected information on provision and organization of CR in hospitals $(n=35)$ and municipalities $(n=98)$ in Denmark. The survey in 2015 had additional items related to migrants, such as provision of interpreter services and multilingual information material.

Results: Not all CR core components were provided by hospitals to non-Danish speaking patients. There was no improvement from 2013 to 2015. Hospitals had full coverage (19/19) of interpreter services compared to 84\% (26/ 31) of municipalities. Provision of multilingual information material was low in hospitals $32 \%(6 / 19)$ and in municipalities 3\% (1/31).

Conclusion: This study found language-related barriers in migrants' access to $C R$, in the form of inadequate provision of CR core components for non-Danish speaking patients at some Danish hospitals and suboptimal provision of interpreter services in municipalities. The findings call for increased attention to language barriers and further studies are needed to map the extent of the problem.
\end{abstract}

Keywords: Cardiac rehabilitation, Migrants, Translations, Language barriers

\section{Background}

Ischemic heart disease (IHD) ranks as the leading cause of mortality and morbidity globally [1]. There is robust evidence that participation in cardiac rehabilitation (CR) following a cardiac event reduces IHD mortality, morbidity and rehospitalisation in addition to improving quality of life $[2,3]$. Correspondingly, CR is recommended in several national and international guidelines $[4,5]$ including the Danish national clinical guideline for

\footnotetext{
* Correspondence: f.al.sharifi@outlook.dk

${ }^{1}$ Section of Immigrant Medicine, Department of Infectious Disease, Copenhagen University Hospital, Ostvej, Pavillion 2, 2650 Hvidovre, Copenhagen, Denmark

Full list of author information is available at the end of the article
}

CR [6], which entitles heart patients to CR in hospitals and in municipalities.

Provision of outpatient CR in Denmark was solely a hospital-based task until 2007. In accordance with the World Health Organization's (WHO) recommendations $[7,8]$; a Danish structural reform led to the delivery of $\mathrm{CR}$ becoming a shared responsibility between hospitals and municipalities [9]. Community-based outpatient services are thought to enhance accessibility by increasing proximity to the provider and thereby potentially diminishing health inequalities among vulnerable population groups. Vulnerability can relate to socioeconomic status, educational level, age, gender or ethnic origin, and have been shown to predict lower uptake of CR [10-12]. A

(c) The Author(s). 2019 Open Access This article is distributed under the terms of the Creative Commons Attribution 4.0 International License (http://creativecommons.org/licenses/by/4.0/), which permits unrestricted use, distribution, and reproduction in any medium, provided you give appropriate credit to the original author(s) and the source, provide a link to the Creative Commons license, and indicate if changes were made. The Creative Commons Public Domain Dedication waiver (http://creativecommons.org/publicdomain/zero/1.0/) applies to the data made available in this article, unless otherwise stated. 
Danish study in 2012 tested an intervention where socially vulnerable groups were offered an extended rehabilitation programme customized to meet their special needs. Non-Danish speaking patients were included in the study and were offered interpretation support. The study suggested that offering socially differentiated $\mathrm{CR}$ can equalize attendance and adherence among socially vulnerable groups [13].

A recent Danish nationwide register study has demonstrated major differences in uptake of hospital-based CR-services between migrants and Danish born patients in the form of fewer contacts for physical exercise and lower initiation of patient education, as well as lower uptake of pharmacological secondary prevention. These findings could not be explained by comorbidity and sociodemographic factors [14]. Other studies have found similar tendencies in uptake of CR among migrants $[12,15,16]$.

Migrants are known to face various barriers in their access to healthcare on an individual level in the form of language, culture, inadequate health literacy and difficulties in navigating the healthcare system [17]. Additionally, barriers can also be found on a structural level including the referral system, limited provision of interpreter services, lack of translated and customized information materials for ethnic minority subgroups, short consultation times and resource constraints $[18,19]$.

Access to healthcare services is defined as the opportunity or ease with which users are able to reach and obtain appropriate services in proportion with their needs. The accessibility of a healthcare service is influenced by factors on an individual level as well as provider and system level [20]. WHO has developed a framework called 'the right to health framework' pointing out four indicators to ensure equality in healthcare, these indicators are accessibility, availability, acceptability and quality of service [21].

Language barriers are among the most common obstacles migrants endure in their access to healthcare, as it can potentially impede effective communication and create misunderstandings, thus posing challenges to providing adequate healthcare. Several international studies have concluded that language barriers hamper access and reduce quality of healthcare [22-24]. However, the use of professional interpreters with non-Danish speaking patients has been associated with improvements in patient satisfaction, clinical outcomes and healthcare access $[22,25,26]$.

Additionally, well-designed information material can improve patients' health knowledge, engagement and patient-doctor communication [27]. A German study from 2016 found that utilization of high-quality multilingual information material was useful among migrants [28]. Hence, the objectives of this study were to examine the provision of core CR components (i.e. exercise training, patient education, nutritional counselling, psychosocial support and smoking cessation support) for migrants and the provision of interpreter services and multilingual materials in hospitals and municipalities.

\section{Methods \\ Study design and setting}

The present study is a survey-based descriptive study. Data on the provision of CR services in hospitals and municipalities in Denmark are based on nationwide surveys conducted by the Danish Cardiac Rehabilitation Database (DHRD) [29] in 2013 and 2015. The Danish healthcare system is publicly financed through taxes and operates across three political and administrative levels, national, regional and local. The state has a regulatory and supervisory function. The state is divided into five regions that are responsible for hospitals, general practitioners and psychiatric care. The regions contain $98 \mathrm{mu}-$ nicipalities that are responsible for providing primary healthcare services [30].

\section{Data collection and respondents}

Information on core components of available cardiac rehabilitation programmes and organization of CR services were collected by way of parallel web-based questionnaires sent out to all hospitals offering CR services $(n=35)$ and all Danish municipalities $(n=98)$. Core components of $\mathrm{CR}$ included exercise training, patient education, psychosocial support, smoking cessation support and nutritional counselling.

The respondents were physicians, nurses, dietitians and physiotherapists, who are part of the multidisciplinary CR team. Each of them had to respond to a section of the questionnaire related to their profession.

The questionnaires were complied using the recommended national clinical guideline regarding the coverage of core CR components. A more detailed description of the survey can be found elsewhere [31]. Hospital-based questionnaires were derived from the DHRD, which collects programme-level CR data. The submission of data is required for hospitals according to Danish Law whereas the participation for the municipalities is optional. A combination of closed-ended and open-ended questions was applied to give respondents the opportunity to elaborate on their answers.

In the present study we used hospital data from 2013 and 2015 to examine provision of CR core components for migrants and data from 2015 to examine the distribution of provision across the five Danish regions, and whether hospital type and percentage of migrants in a hospital's catchment area was related to provision.

The survey from 2015 contained additional questions about socially differentiated $\mathrm{CR}$, socially vulnerable groups including migrants and special offers to these groups. Due to survey design, data on provision of 
interpreter services and multilingual information material was only obtained from hospitals and municipalities that offer socially differentiated CR.

Finally, we investigated factors that could potentially predict the provision of interpreter services and multilingual material. For hospitals, data variables applied were hospital type and percentage of migrants in a hospital's catchment area. Municipality data variables were percentage of migrants and size of population in the municipality.

\section{Definitions}

\section{Migrants}

Migrants are defined by UNESCO as "any person who lives temporarily or permanently in a country where he or she was not born, and has acquired some significant social ties to this country"'.

The survey used in this study was not designed to specifically ask about provision of $\mathrm{CR}$ to migrants, however based on the UNESCO definition of migrants and Denmark's recent immigration history, anyone in Denmark with limited proficiency in Danish or from an ethnic minority background is likely to be a migrant. Hence, migrant involvement in $\mathrm{CR}$ was extrapolated from a positive answer to any one of three questions: 1) provision of CR to patients with limited Danish proficiency; 2) provision of $\mathrm{CR}$ to non-Danish speaking patients or 3) where CR was provided to patients identified as ethnic minorities.

\section{Socially differentiated $C R$}

Socially differentiated $\mathrm{CR}$ was not specifically defined in

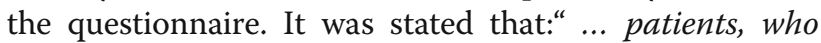
are in need of socially differentiated $C R$, can often be considered vulnerable or at risk of low uptake of CR".

\section{Hospital type}

In 2015, all of the 35 Danish acute care hospitals offered CR. Of those, 18 were university hospitals and 17 were general hospitals.

Data analysis We applied descriptive statistical analysis. To investigate predictors for provision of CR core components, provision of interpreter services and multilingual information material, we dichotomized hospitals into hospitals with low and high proportion of migrants in their catchment area at a cut-off point of $4 \%$ to form two nearly equal-sized groups and according to hospital type (university hospital and general hospital).

Municipalities were dichotomized according to the proportion of migrants in the municipality at a cut-off point of 3,5\% to form two nearly equal-sized groups, and according to population size $(<45.000$ and $>45.000)$.

Fisher's exact test with a significance level of 0.05 was applied to test statistically significant differences between hospitals and municipalities and predictions. Predictors for hospitals' provision of interpreter services were not analysed due to $100 \%$ coverage of interpreter services in all hospitals. Statistical analyses were performed with SAS 9.4 statistical software (SAS Institute Inc., Cary, USA).

\section{Results}

The following core components were included in the surveys in 2013 and 2015: exercise training, patient education, nutritional counselling, psychosocial support and smoking cessation support.

Only the survey from 2015 contained questions about socially differentiated $\mathrm{CR}$ and data on provision of interpreter services and multilingual information was only possible to obtain from hospitals and municipalities offering socially differentiated CR due to survey design. In contrast, the 2013 survey did not contain questions on socially differentiated $\mathrm{CR}$ and the provision of interpreter services and multilingual information material was included as general questions to all hospitals and municipalities.

\section{Response rates and participation}

Response rates for hospitals reached 100 and 96\% for municipalities, of which 100 and 93\% responded that they offer at least one CR core component (Fig. 1).

\section{Provision of core CR components to migrants}

The study found incomplete provision of CR core components to migrants in hospitals. These provision rates were virtually unchanged from 2013 to 2015 (Additional file 1: Table S1). Moreover, in 2015 the provision of each CR core component to migrants in the five Danish regions ranged from 44 to $100 \%$ and none of the regions had full provision of all core components in general (Table 1).

\section{Socially differentiated $\mathrm{CR}$ and vulnerable patient groups}

Socially differentiated CR was offered in $54 \%(n=19 / 35)$ of the hospitals, and in $44 \%(n=31 / 71)$ of the municipalities. Overall migrants were considered vulnerable in up to $84 \%$ of the hospitals, more specifically $74 \%$ were non-Danish speaking patients and $84 \%$ were patients with an ethnic minority background (see definition of migrants in this study in the methods section). The corresponding percentages for municipalities were respectively 58 and $61 \%$. These proportions did not differ considerably in percentage terms from other potentially vulnerable groups such as patients with low education, cognitive disability and those living alone except from those with a long distance to provider. No statistical comparison measure was calculated between groups. There were no significant differences between hospitals and municipalities (Table 2). 


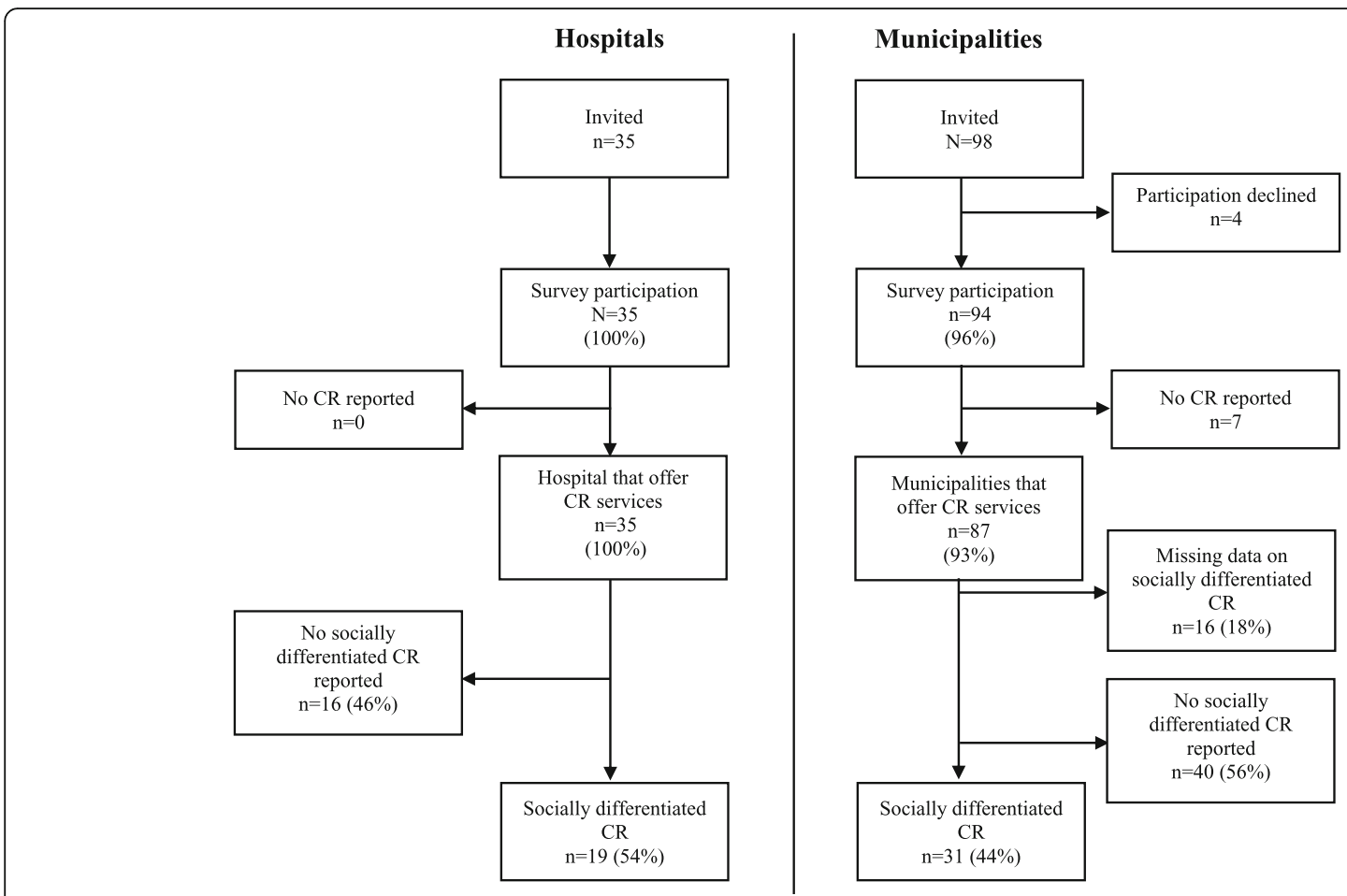

Fig. 1 Shows the participation flowchart in survey on provision of CR in hospitals and municipalities 2015

\section{Interpreter services and information material}

Provision of interpreter services in hospitals reached full coverage, whereas it was lower in percentage terms in municipalities $84 \%(n=26 / 31)$, the difference was not statistically significant. The availability of multilingual information material was low in hospitals $32 \%(n=6 / 19)$ and in municipalities $3 \%(n=1 / 31)$. The difference between hospitals and municipalities was significant $(p=0.009)$ (Table 2).

University hospitals had a higher provision of multilingual information material $44 \%(n=4 / 9)$ than general hospitals $20 \%(n=2 / 10)$, and hospitals with the highest proportions of migrants in their catchment area were more likely to have multilingual information material

Table 1 Provision of CR core components for non-Danish speaking patients by different variables in 2015

\begin{tabular}{|c|c|c|c|c|c|}
\hline & Exercise training & Patient education & Psychosocial support & Smoking cessation support & Nutritional counselling \\
\hline \multicolumn{6}{|l|}{$\%(n / N)$} \\
\hline \multicolumn{6}{|l|}{ Regions } \\
\hline Capital Region of Denmark & $78 \%(7 / 9)$ & $44 \%(4 / 9)$ & $100 \%(8 / 8)$ & $78 \%(7 / 9)$ & $89 \%(8 / 9)$ \\
\hline Central Denmark Region & $100 \%(7 / 7)$ & $100 \%(6 / 6)$ & $100 \%(6 / 6)$ & $67 \%(4 / 6)$ & $100 \%(6 / 6)$ \\
\hline North Denmark Region & $75 \%(3 / 4)$ & $75 \%(3 / 4)$ & $50 \%(2 / 4)$ & $50 \%(2 / 4)$ & $75 \%(3 / 4)$ \\
\hline Region Zealand & $100 \%(6 / 6)$ & $83 \%(5 / 6)$ & $100 \%(5 / 5)$ & $50 \%(3 / 6)$ & $100 \%(6 / 6)$ \\
\hline Region of Southern Denmark & $100 \%(8 / 8)$ & $78 \%(7 / 9)$ & $100 \%(8 / 8)$ & $100 \%(7 / 7)$ & $100 \%(8 / 8)$ \\
\hline \multicolumn{6}{|l|}{ Hospital type } \\
\hline University hospital & $94 \%(17 / 18)$ & $59 \%(10 / 17)$ & $94 \%(15 / 16)$ & $64 \%(11 / 17)$ & $88 \%(15 / 17)$ \\
\hline General hospital & $88 \%(14 / 16)$ & $88 \%(15 / 17)$ & $93 \%(14 / 15)$ & $80 \%(12 / 15)$ & $100 \%(16 / 16)$ \\
\hline \multicolumn{6}{|c|}{ Percentage of migrants in hospitals catchment area } \\
\hline$<4 \%$ & $90 \%(18 / 20)$ & $80 \%(16 / 20)$ & $94 \%(17 / 18)$ & $74 \%(14 / 19)$ & $100 \%(18 / 18)$ \\
\hline$>4 \%$ & $93 \%(13 / 14)$ & $64 \%(9 / 14)$ & $92 \%(12 / 13)$ & $69 \%(9 / 13)$ & $87 \%(13 / 15)$ \\
\hline
\end{tabular}

$n=$ number of hospitals offering CR core component to migrants

$N=$ total number of hospitals offering the CR core component overall 
Table 2 Socially differentiated CR, provision of interpreter services, multilingual information material and vulnerable patients in 2015

\begin{tabular}{llll}
\hline & Hospitals $N=35$ & Municipalities $N=87$ & $p$-value \\
\hline Provide socially differentiated cardiac rehabilitation & $54 \%(19 / 35)$ & $44 \%(31 / 71)$ & $84 \%(26 / 31)$ \\
Provision of interpreter services during rehabilitation & $100 \%(19 / 19)$ & $3 \%(1 / 31)$ & \\
Provision of multilingual information material & $32 \%(6 / 19)$ & $65 \%(20 / 31)$ & 0.1424 \\
Patients considered vulnerable & & $74 \%(23 / 31)$ & 0.009 \\
Low education level & $84 \%(16 / 19)$ & $58 \%(18 / 31)$ & 0.1972 \\
Cognitive disability & $84 \%(16 / 19)$ & $61 \%(19 / 31)$ & 0.4979 \\
Ethnic minority background & $74 \%(14 / 19)$ & $65 \%(20 / 31)$ & 0.3659 \\
Non-Danish speaking patients & $84 \%(16 / 19)$ & $71 \%(22 / 31)$ & 0.1171 \\
Living alone & $84 \%(16 / 19)$ & $77 \%(24 / 31)$ & 0.1972 \\
Limited social network & $89 \%(17 / 19)$ & $29 \%(9 / 31)$ & 0.1699 \\
Multimorbidity & $79 \%(15 / 19)$ & $68 \%(21 / 31)$ \\
Long distance to provider & $47 \%(9 / 19)$ & $65 \%(20 / 31)$ \\
Psychiatric disorder & $84 \%(16 / 19)$ & 0.2331 \\
Alcohol or drug abuse & $84 \%(16 / 19)$ & 0.3203 \\
\hline
\end{tabular}

$67 \%(n=6 / 10)$, although numbers were small. The association between provision of multilingual information material and proportion of migrants in a hospital's catchment area was significant $(p=0.003)$.

Provision of interpreter services was not associated with the proportion of migrants. Municipalities with the largest populations were more likely to offer interpreter services $90 \%(n=19 / 21)$ than the ones with smaller populations $70 \%(n=7 / 10)$ but the difference was not significant (Table 3 ).
Open-ended questions

Some hospital respondents commented in the openended questions that they specifically referred migrants to the municipality where there are customized offers for non-Danish speaking patients.

Open ended responses also revealed that some respondents did not respond to consider migrants as vulnerable in the close-ended questions because they did not want to stereotype patients, but instead performed an individualized assessment of the patients' needs.

Table 3 Predictors of provision of interpreter services in CR at hospitals and in municipalities in 2015

\begin{tabular}{|c|c|c|c|c|}
\hline & Provision of interpreter services & $p$-value & Multilingual information material & $p$-value \\
\hline \multicolumn{5}{|l|}{ Hospitals } \\
\hline Hospital type & * & * & & 0.3498 \\
\hline University Hospital & & & $44 \%(4 / 9)$ & \\
\hline General Hospital & & & $20 \%(2 / 10)$ & \\
\hline Percentage of migrants in hospitals' catchment area & & & & 0.0031 \\
\hline$<4 \%$ & * & * & $0 \%(0 / 9)$ & \\
\hline$>4 \%$ & & & $67 \%(6 / 10)$ & \\
\hline \multicolumn{5}{|l|}{ Municipalities } \\
\hline Percentage of migrants in municipalities & & 1.00 & $* *$ & ** \\
\hline$<3.5 \%(n=42)$ & $83 \%(15 / 18)$ & & & \\
\hline$>3.5 \%(n=45)$ & $85 \%(11 / 13)$ & & & \\
\hline Population size in municipalities & & 0.2955 & $* *$ & $* *$ \\
\hline$<45.000(n=45)$ & $70 \%(7 / 10)$ & & & \\
\hline$>45.000(n=42)$ & $90 \%(19 / 21)$ & & & \\
\hline
\end{tabular}

${ }^{*} p=1.00$

** Not analyzed due to small number $(n=1)$ 


\section{Discussion}

Our study showed that not all hospitals provided non-Danish speaking patients with all CR core components, and no improvement was seen from 2013 to 2015. Hospitals in Denmark had full coverage of interpreter services, compared to $84 \%$ of municipalities. Provision of multilingual information material was low in hospitals $(32 \%)$ and almost absent in municipalities (3\%).

\section{Provision of CR and access for migrants}

According to our results, hospitals did not have full provision of $\mathrm{CR}$ core components to non-Danish speaking patients. Only minor changes in provision of $\mathrm{CR}$ services were observed from the years 2013 to 2015, e.g. the provision of exercise training increased from 91 to 92\%; and the provision of patient education increased from 71 to $74 \%$. These percentages must be interpreted with caution as a few respondents from hospitals explained that they did not exclude non-Danish speaking patients but would refer these patients to municipalities with whom they share responsibility for CR, and therefore had indicated not to provide $C R$ services at the hospital. However, some of the negative responses were left without any comments, and the reasons behind this potential lack of available services needs further investigation. Where language barriers were the reasons given for some hospitals not to provide CR, it would contradict the recommendations of the national clinical guideline for $C R$ [6]. The guideline recommends that $C R$ should be offered to all eligible patients regardless of background and advises providers to be attentive to well-known barriers to participation, such as language. Even though the offer of interpretation is available in theory, this is often organized based on the principal of individual consultation. $\mathrm{CR}$ is group based by nature and therefore people with language barriers could be excluded [32]. The right to equal access to healthcare services is also established in Danish law and international human rights covenants [21,33]. We found a variation in the proportion of hospitals that offered CR to migrants across the five Danish regions; and no region had full provision of core components. A recent Danish study on rehabilitation after brain injury showed regional variations in rehabilitation despite the existence of a national guideline [34]. Together with our findings, this could reflect that the implementation of guidelines can be challenging, and requires monitoring in order to ensure they improve quality in clinical practice [35]. The health system could reduce disparity in healthcare by standardized descriptions of disease management programmes, which are implemented by law, in order that all patients receive treatment of uniform high quality regardless of where they live. This has been proven to be effective in the field of cancer treatment'.

\section{Vulnerability of migrants and provision of interpretation} and multilingual information material

Socially differentiated $\mathrm{CR}$ that focused on vulnerable patients was offered in 54\% of the hospitals, and in $44 \%$ of the municipalities that provided data but, the open-ended answers revealed that there was no uniform understanding of the term. Non-Danish speaking patients and patients with an ethnic minority background were considered vulnerable by 74 and $84 \%$ of responding hospitals respectively. The corresponding percentages were lower for municipalities, 58 and $61 \%$ respectively. These percentages must also be interpreted with caution as some respondents were reluctant to stereotype by certain vulnerability parameters; and would rather do an individual assessment of needs and provide individualized healthcare services. The provision of interpreter services in hospitals reached $100 \%$ whereas it was only $84 \%$ for municipalities. The full coverage in hospitals can be seen in the light of hospitals being legally required to provide interpretation [33], while municipalities are not subject to the section of the Danish Health Act about provision of interpreter services. Municipalities are solely obliged to provide secondary prevention care equal to that of hospitals. The section about interpretation in the Danish Health Act is the only law that explicitly states mandatory use of interpreters specifically aimed at the public hospitals, medical specialists and general practitioners, thereby leaving a gap in other health services outside of these health facilities regarding the provision of interpreter services.

A study in 2012 mapped the provision of interpreter services in 240 health services (48 emergency services, 48 mental health services, and 144 primary care services) across 16 different European countries and found that $42 \%$ of the services did not provide any form of interpretation. Countries that tended to have higher provision of interpreter services had policies and regulations concerning cost of interpretation [36]. It is therefore fair to conclude that legislation on interpretation plays a significant role in the provision. The importance of having a legal framework for language in access to healthcare services has been discussed in the US, and that it should not an impediment to health [37]. Although the Danish and US healthcare systems are not directly comparable, the essence of the message is applicable. The differentiation in the Danish law between hospitals and municipalities seems to be reflected in the provision of interpreter services, albeit it is the very same Danish Health Act that sets out the obligations for shared responsibilities for CR. This has the potential to increase inequality in access for migrants to CR between the two sectors.

An aim of the involvement of municipalities in $\mathrm{CR}$ was to achieve greater equality in health and increase the inclusion of socially vulnerable patients according to 
WHO's vision of "Health in All Policies" [8]. However, it seems that the inclusion of migrants in $\mathrm{CR}$ is inadequate.

Another interesting finding of our study was the very limited availability of multilingual information material reported to be offered by 6 hospitals, mainly concentrated at university hospitals, and hospitals with catchment areas with higher densities of migrants, and only in one municipality. This runs contrary to the findings of a review by Coulter et al. [27] showing major benefits for patient information material.

\section{Strengths and limitations}

The study was not designed specifically to identify migrants, hence this information was extrapolated from information related to non-Danish/limited Danish speakers and ethnic minorities. Ethnic minority does not in all cases mean a migrant, hence there is a small risk the survey overestimated the number of sites providing $\mathrm{CR}$ to migrants. However, given the available data we feel this paper gives a unique insight into existing structural aspects of $C R$ related to migrants. We recommend future studies base survey design on official definitions of migrants.

A strength in this survey design is that the combination of close-ended and open-ended questions made it possible to solicit additional information to gain a more detailed understanding of the quantitative data.

The open-ended answers also demonstrated that items did not always capture the aimed for information, which could be considered as a weakness in the design. Because all data was self-reported, there is a risk that respondents may have reported answers that reflect a greater compliance with the guidelines which might entail information bias that tended to lead to more positive responses.

Another limitation is that we were only able to obtain information on provision of CR from $96 \%$ of the municipalities in contrast to $100 \%$ of the hospitals. This could potentially underestimate the results from the municipalities. Moreover, it was only possible to collect information on interpreter services, multilingual information material and socially vulnerable patients from hospitals and municipalities that offered socially differentiated CR, leading again to a potential underestimation of our results. New surveys will be conducted in 2018, and we plan to include the same items, and this time all hospitals and municipalities are included in order to follow the development on this area.

\section{Conclusion}

In this descriptive study on migrants' access to CR in hospitals and municipalities, we found two barriers to access. Firstly, not all hospitals provided CR core components for non-Danish speaking patients. Secondly, there was not full coverage of interpreter services in municipalities. Furthermore, only a few hospitals and municipalities provided multilingual information material. The observed inequalities in access to CR call for increased awareness in order to ensure effective treatment and prevention for migrants. There seems to be a need for more education and guidance for health professionals on the encounter with patients with a migrant background.

Lastly, there is a need for further studies to evaluate the actual scale of the problem; and to better understand why $\mathrm{CR}$ services are not fully accessible for migrants.

\section{Additional file}

Additional file 1: Table S1. The table shows general provision of core components of cardiac rehabilitation and provision of $\mathrm{CR}$ for migrants at Danish hospitals. (DOCX $16 \mathrm{~kb}$ )

\section{Abbreviations}

CR: Cardiac rehabiliation; DHRD: Danish Cardiac Rehabiliation Database; IHD: Ischemic heart disease; WHO: World Health Organization

\section{Acknowledgements}

We thank Vicky L Joshi for proofreading the manuscript.

\section{Funding}

The study was funded by Department of Infectious Diseases, Copenhagen University Hospital, Hvidovre. The funding body covered the salary of the corresponding author and thus contributed to the analysis and interpretation of data, and to the writing the manuscript.

\section{Availability of data and materials}

Data and materials for this study are kept at the Danish Cardiac Rehabilitation Database.

The datasets analyzed during the current study are not publicly available due to the Danish legislation on data security but are available from the corresponding author upon reasonable request.

\section{Authors' contributions}

HKR provided the data for the study from the DHRH database. HWF and MN designed the study. FA conducted the analysis in collaboration with HKR and $A D$. FA drafted the manuscript. AD, HWF, HKR and MN read and critically revised the manuscript. All authors approved the final manuscript and agree to be accountable for all aspects of work ensuring integrity and accuracy.

\section{Ethics approval and consent to participate}

The project has been approved by the Danish data agency (j.nr. 2014-412922) and approval for allowance of use of survey data from the Danish Cardiac Rehabilitation Database was received in July 2017.

Consent for publication

Not applicable.

\section{Competing interests}

The authors declare that they have no competing interests.

\section{Publisher's Note}

Springer Nature remains neutral with regard to jurisdictional claims in published maps and institutional affiliations.

\section{Author details}

${ }^{1}$ Section of Immigrant Medicine, Department of Infectious Disease, Copenhagen University Hospital, Ostvej, Pavillion 2, 2650 Hvidovre, Copenhagen, Denmark. ${ }^{2}$ Knowledge Centre for Rehabilitation and Palliative Care (REHPA) Odense University Hospital and University of Southern Denmark, Odense, Denmark. ${ }^{3}$ Research Centre for Migration, Ethnicity and Health (MESU), Section of Health Services Research, University of 
Copenhagen, Copenhagen, Denmark. ${ }^{4}$ Department of Internal Medicine, Copenhagen University Hospital, Herlev, Denmark.

\section{Received: 31 July 2018 Accepted: 25 March 2019}

\section{Published online: 11 April 2019}

\section{References}

1. WHO, World health Statistics 2017: monitoring health for the SDGs, sustainable development goals. 2017.

2. Dalal HM, Doherty P, Taylor RS. Cardiac rehabilitation. Bmj. 2015;351:h5000

3. Anderson $L$, et al. Exercise-based cardiac rehabilitation for coronary heart disease. Cochrane Database Syst Rev. (2016, 1):p. Cd001800.

4. NICE. MI - secondary prevention: Secondary prevention in primary and secondary care for patients following a myocardial infarction. CG172. November 2013

5. Piepoli MF, et al. Secondary prevention in the clinical management of patients with cardiovascular diseases. Core components, standards and outcome measures for referral and delivery: a policy statement from the cardiac rehabilitation section of the European Association for Cardiovascular Prevention \& Rehabilitation. Endorsed by the Committee for Practice Guidelines of the European Society of Cardiology. Eur J Prev Cardiol. 2014; 21(6):664-81.

6. Sundhedsstyrelsen, National klinisk retningslinje for hjerterehabilitering, 2013. 2015.

7. WHO Study Group on Integration of Health Care Delivery. Integration of health care delivery: Report of a who study group. 1996.

8. WHO, World Health Organization. Regional office for Europe. Health 2020. A european policy framework and strategy for the 21st century. 2013.

9. Hjertekarrehabilitering efter strukturreformen. Rehabilitering og sammenhængende patientforløb for kronisk syge. Inspiration til kommuner, regioner, almen praksis, sygehuse m.fl. Dansk Cardiologisk Selskab, Danske Regioner, Dansk Selskab for Almen Medicin, Hjerteforeningen, Kommunernes Landsforening, Kræftens Bekæmpelse og Netværk af forebyggende sygehuse i Danmark. 2007.

10. Peters AE, Keeley EC. Trends and predictors of participation in cardiac rehabilitation following acute myocardial infarction: data from the behavioral risk factor surveillance system. J Am Heart Assoc. 2017;7(1).

11. Harlan WR 3rd, et al. Importance of baseline functional and socioeconomic factors for participation in cardiac rehabilitation. Am J Cardiol. 1995;76(1):36-9.

12. Sumner J, Grace SL, Doherty P. Predictors of cardiac rehabilitation utilization in England: results from the National Audit. J Am Heart Assoc. 2016;5(10).

13. Meillier LK, et al. Socially differentiated cardiac rehabilitation: can we improve referral, attendance and adherence among patients with first myocardial infarction? Scand J Public Health. 2012;40(3):286-93.

14. Frederiksen HW, Zwisler A-D, Johnsen SP, Öztürk B, Lindhardt T, Norredam M. Differences in initiation and discontinuation of preventive medications and use of non-pharmacological interventions after acute coronary syndrome among migrants and Danish-born. Eur Heart J. 2018;39(25):2356-64.

15. Banerjee AT, Gupta M, Singh N. Patient characteristics, compliance, and exercise outcomes of south Asians enrolled in cardiac rehabilitation. $J$ Cardiopulm Rehabil Prev. 2007;27(4):212-8.

16. Beswick, A.D., et al., Provision, uptake and cost of cardiac rehabilitation programmes: improving services to under-represented groups. Health Technol Assess, 2004. 8(41): p. iii-iv, ix-x, 1-152

17. Chauhan $U$, et al. Exploring uptake of cardiac rehabilitation in a minority ethnic population in England: a qualitative study. Eur J Cardiovasc Nurs. 2010;9(1):68-74

18. Scheppers $\mathrm{E}$, et al. Potential barriers to the use of health services among ethnic minorities: a review. Fam Pract. 2006;23(3):325-48.

19. DiGiacomo ML, et al. 'I don't know why they don't come': barriers to participation in cardiac rehabilitation. Aust Health Rev. 2010;34(4):452-7.

20. Levesque JF, Harris MF, Russell G. Patient-centred access to health care: conceptualising access at the interface of health systems and populations. Int J Equity Health. 2013;12:18.

21. UN Committee on Economic, Social and Cultural Rights (CESCR), General Comment No. 14: The Right to the Highest Attainable Standard of Health (Art. 12 of the Covenant), 11 August 2000, E/C.12/2000/4, available at: https://www.refworld.org/docid/4538838d0.html. [Accessed 7 Apr 2019]

22. Jacobs EA, et al. Overcoming lanquage barriers in health care: costs and benefits of interpreter services. Am J Public Health. 2004;94(5):866-9.
23. Woloshin $\mathrm{S}$, et al. Is language a barrier to the use of preventive services? J Gen Intern Med. 1997;12(8):472-7.

24. Carrasquillo $\mathrm{O}$, et al. Impact of language barriers on patient satisfaction in an emergency department. J Gen Intern Med. 1999;14(2):82-7.

25. Karliner $\mathrm{LS}$, et al. Do professional interpreters improve clinical care for patients with limited English proficiency? A systematic review of the literature. Health Serv Res. 2007;42(2):727-54.

26. Flores $\mathrm{G}$. The impact of medical interpreter services on the quality of health care: a systematic review. Med Care Res Rev. 2005;62(3):255-99.

27. Coulter A, Ellins J. Effectiveness of strategies for informing, educating, and involving patients. Bmj. 2007:335(7609):24-7.

28. Holzel LP, et al. Effects of culture-sensitive adaptation of patient information material on usefulness in migrants: a multicentre, blinded randomised controlled trial. BMJ Open. 2016;6(11):e012008.

29. Dansk Hjerterehabiliteringsdatabase (DHRD). Dokumentalistrapport, version 1.2. March 2015

30. Ministry of Health [Denmark]. Health care in Denmark: an overview. 2017. Retrieved from https://www.sum.dk/English/ /media/Filer\%20\%20Publikationer_i_pdf/2016/Healthcare-in-dk-16-dec/Healthcare-englishV16-dec.ashx. [Accessed 7 Apr 2019]

31. Lindstrom Egholm, C., et al., Implementation of a politically initiated national clinical guideline for cardiac rehabilitation in hospitals and municipalities in Denmark. 2017.

32. Ingholt, L., et al., Socialdifferentieret hjerterehabilitering i praksis. 2016.

33. Sundhedsloven (The Danish Health Act). 2005. https://www.retsinformation.dk/ Forms/R0710.aspx?id=203757\#id1a9bb836-a6d3-4fe4-b99a-55d39c0559f0. [Accessed 4 Apr 2019]

34. Sundhedsstyrelsen. Servicetjek af genoptrænings-og rehabiliteringsindsatserne til mennesker med hjerneskade. 2017.

35. Gagliardi AR, et al. Developing a checklist for guideline implementation planning: review and synthesis of guideline development and implementation advice. Implement Sci. 2015;10:19.

36. Kluge $U$, et al. Health services and the treatment of immigrants: data on service use, interpreting services and immigrant staff members in services across Europe. Eur Psychiatry. 2012;27(Suppl 2):S56-62.

37. Chen AH, Youdelman MK, Brooks J. The legal framework for language access in healthcare settings: title VI and beyond. J Gen Intern Med. 2007; 22(Suppl 2):362-7.

\section{Ready to submit your research? Choose BMC and benefit from:}

- fast, convenient online submission

- thorough peer review by experienced researchers in your field

- rapid publication on acceptance

- support for research data, including large and complex data types

- gold Open Access which fosters wider collaboration and increased citations

- maximum visibility for your research: over $100 \mathrm{M}$ website views per year

At $\mathrm{BMC}$, research is always in progress.

Learn more biomedcentral.com/submission 